\title{
Gasos Guínicos \\ Dermatosis purpúrica pigmentaria, variante granulomatosa, a propósito de un caso
}

\author{
Carolyn Rodríguez ${ }^{1}$, Catalina Silva² ${ }^{2}$ Laura Carreño ${ }^{3}$
}

\section{RESUMEN}

La dermatosis purpúrica pigmentaria (DPP) corresponde a un grupo de enfermedades caracterizadas clínicamente por petequias y coloración bronce de la piel. Generalmente se localiza en las extremidades inferiores y se describen varios tipos, dentro de los cuales se encuentra la variante granulomatosa. Se trata de una dermatopatía benigna, poco frecuente, de etiología aún no precisada y de difícil manejo. Se presenta el caso de una paciente de 48 años, sexo femenino, sin antecedentes mórbidos, que es derivada a dermatología desde reumatología, con el diagnóstico clínico de vasculitis, por la aparición de lesiones maculares y papulares eritematovioláceas, confluentes y pruriginosas en extremidades. Presenta todos sus exámenes normales. Se planteó, entonces, una acroangiodermatitis o liquen plano. Sin embargo, fue necesario llegar al estudio histopatológico para llegar al diagnóstico de dermatosis purpúrica pigmentaria, variante granulomatosa.

Si bien se considera que la DPP granulomatosa es una entidad poco frecuente, la literatura sugiere que es una entidad subdiagnosticada. Se debe plantear como diagnóstico diferencial de lesiones cutáneas en extremidades inferiores, lo que determina la importancia de realizar el estudio histopatológico. De esta forma, la DPP granulomatosa será cada vez más común y se plantearán alternativas de tratamiento mejores a las actuales.

Palabras claves: Dermatosis purpúrica pigmentaria; variante granulomatosa; dermatosis purpúrica pigmentaria granulomatosa; hiperpigmentación extremidades inferiores.

\section{SUMMARY}

The pigmented purpuric dermatoses are a group of diseases characterized clinically by petechiae and bronze skin color, usually affecting the lower extremities. Several types are described and one of them is the granulomatous variant. This is a still rare and benign skin disease of unknown etiology. We present the case of a 48 years old female, previously healthy, derived from rheumatology to dermatology, with the clinical diagnosis of vasculitis due to the presence of confluent erythematous macular and papular lesions, mildly pruritic in lower extremities. Her tests were all in normal ranges. Therefore, an acroangiodermatitis or lichen planus were considered. However, it was necessary to perform a histopathology study to reach the final diagnosis of granulomatous pigmented purpuric dermatosis.

It is considered that Granulomatous DPP is a rare entity, but the literature suggests that it is underdiagnosed. It should always be considered as a differential diagnosis of cutaneous lesions located in lower extremities, which determines the importance of histopathology. Thus, the granulomatous DPP will become more common and will be posible to propose better treatment alternatives.

Key words: Pigmented purpuric dermatosis; Granulomatous variant; Granulomatous pigmented purpuric dermatosis; Lower extremities hyperpigmentation
$\mathrm{L}$ a dermatosis purpúrica pigmentaria (DPP) corresponde a un grupo de enfermedades caracterizadas clínicamente por petequias, coloración bronce de la piel y ocasionalmente telangectasias simé-

'Dermatóloga Clínica Quilín Universidad de Chile, profesor instructor dermatología Universidad de Chile, Santiago, Chile. ${ }^{2}$ Médico CESFAM Vitacura, Universidad de los Andes, Santiago, Chile. ${ }^{3}$ Anatomopatóloga y Profesor Asociado del Departamento de Anatomía Patológica de la Universidad de Chile y Hospital Clínico U. de Chile, Santiago, Chile.

Correspondencia: Catalina Silva. Correo electrónico: catasilva87@gmail. com. Celular: +56 99199117. Dirección: Lenca 9878, Vitacura, Santiago, Chile. Código Postal: 7650172. tricas, en ausencia de insuficiencia venosa o desórdenes hematológicos. ${ }^{1,2,3}$ Histológicamente, las características que definen esta condición son el infiltrado linfocítico angiocéntrico, extravasación de glóbulos rojos hacia la dermis superficial y hemosiderina. No hay vasculitis. ${ }^{4}$ Generalmente se localiza en las extremidades inferiores y se describen varios tipos, como el púrupura pigmentario progresivo, púrpura de Majocchi, púrpura liquenoide de Gougerot y Blum, entre otros. ${ }^{4}$ La variante granulomatosa, es una dermatopatía poco frecuente y de difícil manejo. 


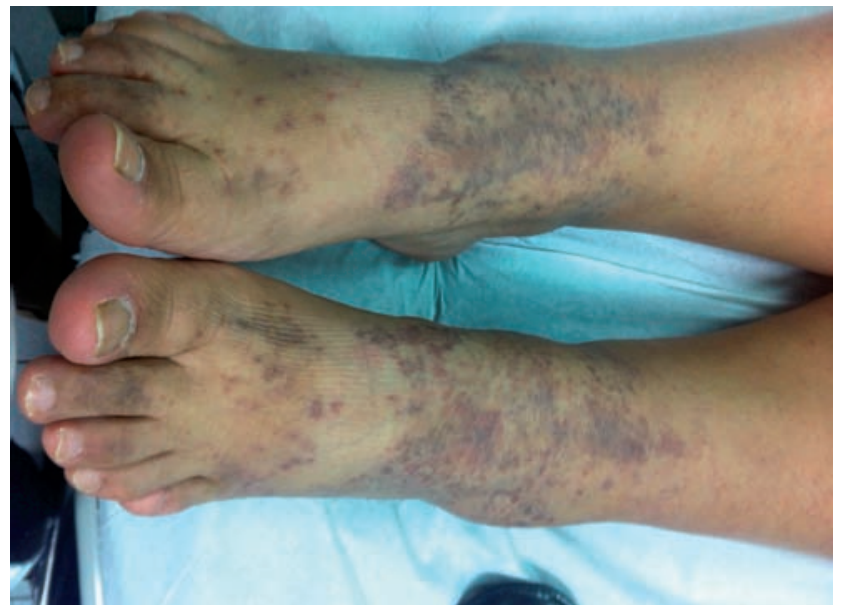

Figura 1

Dermatosis purpúrica pigmentaria granulomatosa. Lesiones papulares eritematovioláceas que confluyen formando placas.

\section{REPORTE DE GASO}

Reportamos el caso de una paciente de 48 años, sexo femenino, sin antecedentes mórbidos, que consulta a reumatología por cuadro de 18 meses de evolución caracterizado por aparición de máculas y pápulas eritematovioláceas, confluentes y pruriginosas en extremidades, predominantemente en extremidades inferiores, haciendo el diagnóstico clínico de vasculitis (Figura 1). Se le realizan exámenes sanguíneos, dentro de los cuales destacan factor reumatoídeo, anticuerpos antinucleares (ANA), anti DNA, complemento, hemograma, orina completa, todos normales. Luego consulta a dermatología, planteándose los diagnósticos clínicos iniciales de acroangiodermatitis o liquen plano. Se realiza el estudio histopatológico, que evidencia un infiltrado inflamatorio liquenoide en la dermis superficial (en "banda"), constituido por linfocitos y grupos de histiocitos, además glóbulos rojos extravasados. Además, se observó una epidermis que presenta leve hiperqueratosis y acantosis (Figura 2). Estos hallazgos fueron compatibles con el diagnóstico de una Dermatosis Purpúrica Pigmentaria, variante granulomatosa. Se inicia tratamiento con prednisona oral 0,5 $\mathrm{mg} / \mathrm{kg}$ durante dos semanas, disminuyendo gradualmente la dosis con buena respuesta, caracterizada por disminución del prurito y cantidad de lesiones. En las lesiones que recidivaron, se indicó clobetasol $0,05 \%$ tópico, con respuesta parcial.

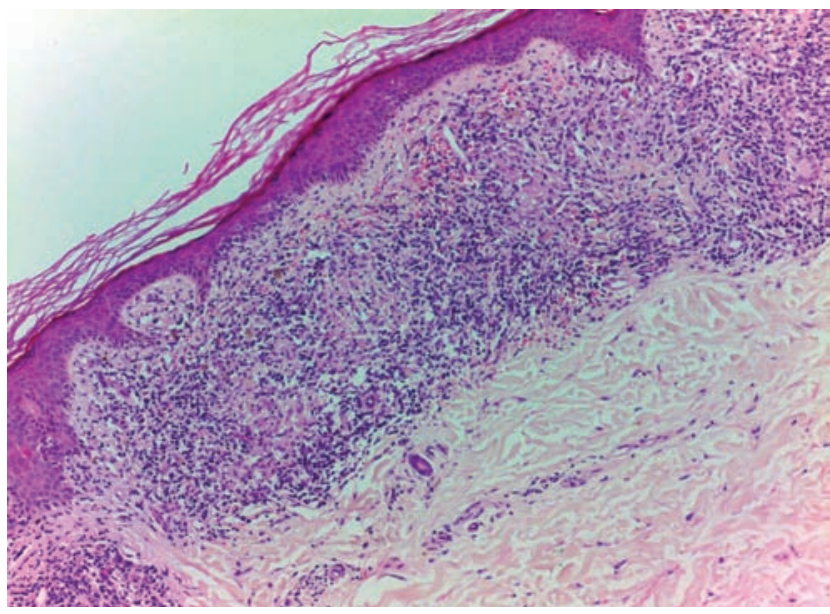

Figura 2

Dermis papilar expandida con un infiltrado celular liquenoide (HEE 40X).

\section{Discusión}

La DPP puede presentarse como una lesión única, localizada típicamente en extremidades inferiores u, ocasionalmente, se presenta de forma difusa. Dependiendo de la extensión y de la morfología clínica, se reconocen distintas variantes ${ }^{1,4,5,6}$ (Tabla 1$)$.

La DPP aún no tiene etiología esclarecida, pero ha sido asociada con estasia venosa, ejercicio, diabetes mellitus, artritis reumatoide, lupus eritematoso, disfunción tiroidea, neoplasias, enfermedades hematológicas, infecciones hepáticas y algunos medicamentos como los antiinflamatorios no esteroidales, sedantes, antihipertensivos, antihistamínicos, hipolipemiantes orales, hipoglicemiantes orales, anticonceptivos inyectables, pseudoefedrina y suplementos de creatinina. ${ }^{1,2,3}$

La variante granulomatosa fue primera vez descrita en 1996 por Saito y Matsuoa. Hasta el 2015 se habían reportado 17 casos en la literatura, casi exclusivamente en pacientes de Asia Oriental, pero se sabe que puede afectar todas las razas y 9 de ellos presentaron hiperlipidemia. ${ }^{4,7,8}$ Las edades más afectadas son desde los 22 a 66 años, con una edad promedio de 51 años. La DPP granulomatosa puede que no sea tan rara como sugiere la literatura, si no más bien sería sub-diagnosticada. ${ }^{4}$ Se trata de una entidad benigna, generalmente asintomática, que tiende a ser crónica con períodos de remisión. ${ }^{2}$ No se ha establecido una etiología clara, pero se ha descrito asociación con la hepatitis C, la enfermedad de Crohn, 
la hipertensión venosa, fragilidad capilar, infecciones y drogas como el acetaminofeno, aspirina, clordiazepóxido, glipizida, hidralazina, tiamina, interferón alfa, entre otros. Además, se piensa que la DPP granulomatosa puede ser inducida por alergia de contacto, ingesta de alcohol e hiperlipidemia. Esta última, sería secundaria a una reacción inflamatoria de la microvascularutra inducida por los lípidos, pero requiere de mayores estudios para demostrar esa asociación., ${ }^{4,8}$ Otra asociación que toma cada vez más importancia, son las enfermedades autoinmunes, encontrándose en un 29\% de los pacientes ANA y factor reumatoídeo positivos. ${ }^{9}$ Nuestra paciente, no tenía ningún antecedente de fármacos asociados y los exámenes estuvieron todos normales.

Histopatológicamente, se evidencia una extravasación de glóbulos rojos en la dermis papilar superficial con depósitos de hemosiderina (contrario a lo que se observa en la dermatosis pigmentada por estasis) y, lo que es propio de la variante granulomatosa, un infiltrado linfohistiocitario con la formación de granulomas en la dermis papilar. Además, se puede observar edema endotelial, sin vasculitis. ${ }^{4,5,8}$

El diagnóstico diferencial de la DPP granulomatosa, principalmente histopatológico, incluye la micosis fungoide, la vasculitis granulomatosa, la reacción granulomatosa a drogas, sarcoidosis e infecciones por mycobaterias atípicas y hongos. ${ }^{1,8}$

1) La micosis fungoide muestra una amplia variedad de manifestaciones cutáneas y puede imitar a un púrpura pigmentado. En las etapas tempranas puede ser histológicamente similar a la DPP, por lo que algunas pistas específicas de la clínica e histopatología pueden ayudar a llegar al diagnóstico correcto. Clínicamente, cuando hay parches o placas purpúricas de gran tamaño o confluentes y/o cuando hay cambios poiquilodermatósicos asociado a prurito, debe sospecharse micosis fungoide. Histológicamente, la micosis fungoide presenta las colecciones de Pautrier's y/o linfocitos grandes, atípicos, cerebriformes en la epidermis.

2) La vasculitis granulomatosa puede parecerse histopatológicamente, pero en la DPP granulomatosa no se ve una vasculitis auténtica.

3) La reacción granulomatosa a drogas presenta eosinófilos, células plasmáticas, linfocitos suprabasales, disqueratosis e inflamación peri-ecrina, elementos ausentes en la DPP granulomatosa. Además, las lesiones tienen una correlación temporal con la ingesta de la droga y al suspenderla, las lesiones desaparecen.

4) La sarcoidosis es otro diagnóstico diferencial, pero no existe ningún examen que sea lo suficientemente específico para hacer el diagnóstico. Por esto, el diagnóstico se puede hacer solo en la presencia de un cuadro clínicohistopatológico compatible, además de la exclusión de otras potenciales etiologías.

5) Las infecciones por micobacterias atípicas y hongos pueden confundirse con el diagnóstico de la DPP variante granulomatosa. Sin embargo, el infiltrado linfohistiocitario se extiende más profundamente y, por lo general, los granulomas presentan caseificación central.

El diagnóstico diferencial de la DPP granulomatosa es muy amplio. Se debe hacer un análisis de la clínica, histología e inmunohistoquímica. ${ }^{1}$

Hasta el momento no existe un tratamiento estándar. Si se identifica un agente etiológico, debe suspenderse y puede resolverse el cuadro. Se han usado protectores vasculares para reducir la permeabilidad capilar como la vitamina $\mathrm{C}$ con resultados variables. El prurito se alivia con corticoides tópicos y antihistamínicos orales. La estasia venosa se puede mejorar con medias elásticas y evitando las prolongadas estadías en posición de pie. Las lesiones pigmentadas responden parcialmente a corticoides tópicos por 4-6 semanas. También se ha probado con PUVA, griseofulvina, pentoxifilino y ciclosporina, pero son pocos estudios que los avalan., ${ }^{4,10}$ Nuestra paciente fue tratada con corticoides orales en primera instancia disminuyendo el prurito y las lesiones y, posteriormente, con corticoides tópicos localmente.

\section{Conclusión}

Existen varios tipos de dermatosis purpúrica pigmentaria y una variante es la granulomatosa. Según la literatura, se trataría de una de las formas con menor incidencia y, por ende, es poco frecuente. Sin embargo, se considera que es una entidad subdiagnosticada, por lo que se debe tener en consideración al momento de hacer el diagnóstico diferencial de lesiones cutáneas en extremidades inferiores. Esto determina la importancia de realizar el estudio histopatológico de dichas lesiones, para que la variante granulomatosa de las DPP sea cada vez más común y se logre proponer alternativas de tratamiento mejores a las actuales. 
Tabla 1.

\begin{tabular}{|c|c|c|c|}
\hline Nombre & Clínica & Histopatología & Tratamiento \\
\hline $\begin{array}{l}\text { Enfermedad de } \\
\text { Schamberg o } \\
\text { púrpura pigmen- } \\
\text { taria progresiva }\end{array}$ & $\begin{array}{l}\text { Lesiones tipo pimienta en } \\
\text { extremidades inferiores, } \\
\text { curso crónico por lo gene- } \\
\text { ral, prurito escaso o nulo }\end{array}$ & $\begin{array}{l}\text { Inflamación linfocítica perivascular } \\
\text { superficial con aumento de capilares y } \\
\text { siderófagos en la dermis superficial. }\end{array}$ & $\begin{array}{l}\text { Corticoides tópicos y sistémicos, vitamina } \\
\mathrm{C} \text { y agentes antiinflamatorios tópicos y } \\
\text { sistémicos. }\end{array}$ \\
\hline $\begin{array}{l}\text { Púrpura anular } \\
\text { telangiectásico } \\
\text { de Majocchi }\end{array}$ & $\begin{array}{l}\text { Máculas o placas anulares } \\
\text { eritematosas en glúteos, } \\
\text { tronco y extremidades } \\
\text { proximales }\end{array}$ & $\begin{array}{l}\text { Capilaritis con infiltrado perivascular } \\
\text { linfocitario con extravasación de hema- } \\
\text { tíes seguida de depósito de hemosideri- } \\
\text { na en los macrófagos. }\end{array}$ & $\begin{array}{l}\text { Disminución de estasis venosa en extremi- } \\
\text { dades, corticoides tópicos. También se han } \\
\text { empleado de forma ocasional pentoxifilina, } \\
\text { rutósido, griseofulvina, ácido ascórbico e } \\
\text { isoflavonas. }\end{array}$ \\
\hline $\begin{array}{l}\text { Púrpura lique- } \\
\text { noide de Gouge- } \\
\text { rot y Blum }\end{array}$ & $\begin{array}{l}\text { Pápulas tipo liquen plano } \\
\text { con la superposicion de } \\
\text { púrpura }{ }^{1} \text {, generalmente } \\
\text { en piernas, zona baja de } \\
\text { tronco y ocasionalmente } \\
\text { en brazos } 5\end{array}$ & $\begin{array}{l}\text { Mayor compromiso de epidermis con } \\
\text { licuefacción de membrana basal espon- } \\
\text { giosis, hiperqueratosis y paraqueratosis }{ }^{5} \text {. }\end{array}$ & $\begin{array}{l}\text { Corticoides tópicos potentes. Los tratamien- } \\
\text { tos con griseofulvina, ciclosporina, ácido } \\
\text { ascórbico, rutósido, fototerapia, han sido } \\
\text { descritos con resultados favorables, sin que } \\
\text { aún se compruebe su verdadera utilidad }\end{array}$ \\
\hline Liquen aureus & $\begin{array}{l}\text { Placas induradas doradas } \\
\text { generalmente bilateral, } \\
\text { en tobillos de hombres } \\
\text { jóvenes, prurito escaso al } \\
\text { inicio }^{1}\end{array}$ & $\begin{array}{l}\text { Denso infiltrado linfohistiocitario en } \\
\text { banda en dermis superficial, en ocasio- } \\
\text { nes más acentuado a nivel perivascular } \\
\text { y perianexial. La extravasación hemáti- } \\
\text { ca es variable, con depósitos de hemosi- } \\
\text { derina dispersos. Se observan también } \\
\text { macrófagos y células de Langerhans. A } \\
\text { diferencia de otras púrpuras pigmenta- } \\
\text { rias crónicas la epidermis es normal y } \\
\text { no hay licuefacción basal. }\end{array}$ & $\begin{array}{l}\text { No hay tratamiento eficaz, pudiendo ocurrir } \\
\text { resolución espontánea entre } 1 \text { y } 12 \text { años. } \\
\text { Habitualmente no responde al tratamiento } \\
\text { con corticosteroides, aunque pueden mejo- } \\
\text { rar el prurito y el componente inflamatorio } \\
\text { sin alterar la pigmentación }\end{array}$ \\
\hline $\begin{array}{l}\text { Púrpura prurigi- } \\
\text { noso o eccema- } \\
\text { toso de Doucas y } \\
\text { Kapetanakis }\end{array}$ & $\begin{array}{l}\text { Eccema y púrpura, in- } \\
\text { tenso prurito, evoluciona } \\
\text { con remisiones y recaídas } \\
\text { espontáneas }\end{array}$ & $\begin{array}{l}\text { Características clásicas de las DPP y se } \\
\text { agrega espongiosis }^{1}\end{array}$ & $\begin{array}{l}\text { Se ha intentado como en otras DPP con } \\
\text { bioflavonoides, ácido ascórbico, dobesilato } \\
\text { de calcio. Como tratamiento sintomático, } \\
\text { pueden indicarse antihistamínicos orales y } \\
\text { corticoides tópicos para aliviar el prurito. }\end{array}$ \\
\hline $\begin{array}{l}\text { Dermatosis pur- } \\
\text { púrica pigmenta- } \\
\text { ria transitoria o } \\
\text { Enfermedad de } \\
\text { Schamberg-like. }\end{array}$ & $\begin{array}{l}\text { Similar a la Enfermedad } \\
\text { de Schamberg, pero se } \\
\text { asocia a prurito intenso, } \\
\text { durando entre } 3 \text { meses a } \\
2 \text { años }\end{array}$ & Similar a la Enfermdad de Schamberg & $\begin{array}{l}\text { Similar a la Enfermedad de Schamberg y } \\
\text { antihistamínicos para el prurito. }\end{array}$ \\
\hline $\begin{array}{l}\text { Dermatosis pur- } \\
\text { púrica pigmenta- } \\
\text { ria lineal }\end{array}$ & $\begin{array}{l}\text { Muy infercuente, predo- } \\
\text { mina en hombres de } 7 \text { a } \\
38 \text { años, en particular en } \\
\text { extremidades inferiores. } \\
\text { La mayoría remite espon- } \\
\text { táneamente en algunos } \\
\text { meses }\end{array}$ & Similar a otras púrpuras pigmentarios & $\begin{array}{l}\text { No existe tratamiento estandarizado, a } \\
\text { pesar que casos aislados respondieron } \\
\text { a griseofulvina, pentoxifilina, PUVA o } \\
\text { protectores vasculares como la vitamina C. } \\
\text { Se pueden usar medidas generales como el } \\
\text { reposo relativo, medias elásticas, emolientes } \\
\text { y tratamiento sintomático si hubiese prurito. }\end{array}$ \\
\hline $\begin{array}{l}\text { Púrpura } \\
\text { gravitacional o } \\
\text { dermatitis ocre } \\
\text { de Favre }\end{array}$ & $\begin{array}{l}\text { Lesiones limitadas a } \\
\text { extremidades inferiores y } \\
\text { asociada a insuficiencia } \\
\text { venosa }\end{array}$ & $\begin{array}{l}\text { Proliferación de células endoteliales, } \\
\text { vasos de paredes gruesas, con pa- } \\
\text { trón lobular y pericitos en la dermis. } \\
\text { Extravasacion de eritrocitos, depósitos } \\
\text { de hemosiderina, fibrosis dérmica, } \\
\text { pequeños trombos en el lumen de vasos } \\
\text { e infiltrado superficial de linfocitos, } \\
\text { histiocitos y células plasmáticas. }\end{array}$ & $\begin{array}{l}\text { Medidas para evitar estasia venosa y corti- } \\
\text { coides tópicos. Se ha intentado eritromicina } \\
\text { oral } 500 \mathrm{mg} \text { cada } 6 \text { horas o dapsona } 50 \\
\text { mg cada } 12 \text { horas por } 3 \text { meses con buenos } \\
\text { resultados. }\end{array}$ \\
\hline
\end{tabular}




\section{REFERENCIAS BIBLIOGRÁFICAS}

1. Kaplan J, Burgin S, Sepehr A. Granulomatous pigmented purpura: report of a case and review of the literature. J Cutan Patol 2011; 38:984-9

2. Lee SH, Kwon JE, Lee KG, Roh MR. Granulomatous variant of chronic pigmented purpuric dermatosis associated with hyperlipidaemia. J Eur Acad Dermatol Venereol 2010; 24;1243-5

3. Ehsani AH, Ghodsi SZ, Nourmohammad-Pour P, Aghazadeh N, Damavandi MR. Pigmented purpura dermatosis and viral hepatitis: a case-control study. Australas J Dermatol 2013; 54:225-7

4. MacQuarrie E.K, Pasternak S, Torok M, Veerassamy S, Walsh N.M.G. Persistent pigmented purpuric dermatitis: granulomatous variant. J Cutan Pathol 201 1; 38:979-83

5. Allevato M.A. Dermatosis purpúricas pigmentarias (capilaritis). Act Terap Dermatol 2007; 30:222-31
6. Magro CM, Schaefer JT, Crowson AN, Li J, Morrison C. Pigmented purpuric dermatosis. Clasification by phenotypic and molecular profiles. Am J Clin Pathol 2007; 128:218-29

7. Sharma L, Gupta S. Clinicoepidemiological study of pigmented purpuric dermatoses. Indian Dermatol Online J 2012; 3(1):1 7-20

8. Battle LR, Shalin SC, Gao L. Granulomatous pigmented purpuric dermatosis. Clin Exp Dermatol 2015; 40(4):387-90

9. Wakusawa C, Fujimura T, Haga T, Aiba S. Granulomatous pigmented purpuric dermatitis associated with primary Sjögren's Syndrome. Acta Derm Venereol 2013; 93:95-6

10. Mun JH, Jwa SW, Song M, Kim HS, Ko HC, Kim BS, et al. Extensive pigmented purpuric dermatosis successfully treated with pentoxifilino. Ann Dermatol 2012; 24(3):363-5 